\title{
LA POBREZAFILIA. LA PORNIFICACIÓN DE LA POBREZA EN AMÉRICA LATINA
}

\section{POVERTYPHILIA. THE PORNIFICATION OF POVERTY IN LATIN AMERICA}

\section{Paula Sequeira Rovira*}

RESUMEN

Este artículo pretende debatir sobre la pobrezafilia, es decir, sobre la exposición fotográfica sensualizada de mujeres en viviendas pobres de América Latina. En dichas imágenes, la ambientación que muestra la clase social baja de sus protagonistas tiene, inclusive, mayor importancia que los mismos cuerpos de estas jóvenes. Para hacer el análisis se estudiaron diversas imágenes que aparecieron en internet bajo este descriptor, así como otros documentos que han servido para contextualizar parte de los antecedentes relacionados a la producción de deseo de este tipo de imágenes eróticas.

PALABRAS CLAVE: PORNOGRAFÍA * POBREZA * SEXUALIDAD * CUERPO * IMÁGENES

\section{ABSTRACT}

This article aims to discuss about povertyphilia (pobrezafilia), that is to say, the sensualized photographic exhibition of women in poor housing in Latin America. In these images, the setting that shows the lower social class of its protagonists is even more important than the bodies of these young women. To carry out the analysis, various images that appeared on the internet under this descriptor were studied, as well as other documents that have served to contextualize part of the antecedents related to the production of desire for this type of erotic images.

KEYWORDS: PORNOGRAPHY * POVERTY * SEXUALITY * BODY * ILLUSTRATIONS 


\section{INTRODUCCIÓN}

Como parte de una tradición histórica que nos ha sido heredada, las fotos de las mujeres desnudas, semi desnudas o en poses erotizadas son parte del ambiente cotidiano de las sociedades actuales, en donde el sexo, más que un negocio, es parte del bagaje cultural que intenta escudriñarse por la mayor cantidad de espacios posibles. Ya sea que aparezcan en escenas de cintas pornográficas, en revistas, en periódicos de sucesos o en la última película de moda, estas imágenes inundan muchos rincones del mundo público y privado. Su enganche se encuentra en los cánones que están afianzados en estándares cercanos a aquellos simbolismos que provienen, entre otros lugares, de la pornografía tradicional: grandes senos, cuerpos esbeltos, torsiones sugerentes, pieles bronceadas, miradas a la cámara, ropas provocativas, mujeres jóvenes, cabellos largos y lisos. Todo lo anterior se ha convertido en emblemas del erotismo y la sensualidad femenina. Da igual si las fotografías sirven para promocionar una carrera actoral, para vender un enjuague bucal, para comercializar una revista o para adornar un calendario. Lo cierto es que este tipo de iconografías saturan una gran cantidad de espacios actuales.

Entre tanta imagen de figuras erotizadas de mujeres que aparecen por doquier, emerge otra forma relativamente reciente de retratos que ha llamado la atención de muchos pero que ha generado relativamente poca reflexión teórica de la academia. Se trata de una situación que tiene un fuerte asidero en Latinoamérica, y que sigue los mismos patrones de sensualidad pornográfica, pero donde se emplean modelos y escenarios muy diferentes a los que cualquier campaña publicitaria o revista de pornografía se atreve o se interesaría en mostrar. Este fenómeno se llama la pobrezafilia y presenta, principalmente, a mujeres en poses sensuales, pero en entornos que dejan entrever la extracción humilde de la protagonista y su clase social. Los seguidores de esta tendencia buscan encontrar las últimas fotografías o videos de aquellas mujeres jóvenes que muestran una ambientación localizada en barrios pobres o casas sencillas, pero haciendo un uso erotizado de sus cuerpos.

Sin duda alguna, la pobreza y sus consecuencias continúan siendo un tema de análisis necesario para las ciencias sociales. Sin embargo, quizá por las serias implicaciones que tiene la reproducción no planificada en sectores económicamente vulnerables de América Latina, los esfuerzos investigativos en sexualidad se han enfocado en analizar aspectos relacionados con la anticoncepción, la fecundidad, el embarazo no deseado o el contagio de infecciones de transmisión sexual (PachecoSánchez, 2015; Fernández, 2011; Di Cesare, 2007; Rostagnol, 2003). Este tipo de investigaciones buscan remarcar las vulnerabilidades que provocan estas situaciones que tienden a perpetuar el círculo de la pobreza, particularmente en las mujeres. Al tener menor acceso a métodos anticonceptivos modernos, informaciones menos accesibles y encuentros sexuales sin protección a edades muy tempranas, las posibilidades de tener mayores oportunidades laborales, educativas y culturales se ven limitadas. Sin embargo, el análisis en temas de sexualidad en este sector debe extenderse a otro tipo de consideraciones. En este caso, se le dará prioridad a la interpretación y los simbolismos de fotografías erotizadas de mujeres en entornos económicamente vulnerables, teniendo en cuenta que esta ha sido una temática poco trabajada desde la academia.

Sin pretender sugerir una unicausalidad del fenómeno, este artículo utilizará elementos del legado que provino de la revista Playboy para promover la inundación de imágenes eróticas y erotizadas desde mediados del siglo 20. Aunque, sin duda, también se podría teorizar sobre otro tipo de influencias como las películas pornográficas tradicionales, las ideas estereotipadas de la belleza femenina o la publicidad y la importancia de las redes sociales o las complejidades del anonimato generadas luego de publicar comentarios o fotografías en estos espacios, por mencionar algunos elementos de este fenómeno. En la actualidad somos herederos de una cierta sensibilidad que fabrica no solo estas iconografías, sino también al sujeto deseante que estandariza con frenesî 
este goce de especificidades normalizadas en el cuerpo de las mujeres. Quienes desean ser fotografiadas, ya sea para vivir de ello o para ser admiradas, también son parte de este proceso normalizador.

La pornografía o, al menos, sus códigos de representación se han convertido en parte de los estándares de sensualidad y erotismo más representativos. Tal y como lo ha señalado Wolf (2002), la producción de una cierta imaginería de "belleza" que es alentada por esta industria confabula con la masificación de estos estándares normalizadores desde la aparición de los daguerrotipos y las fotografías en los que se inició mostrando cuerpos erotizados de mujeres. En este sentido, la situación que se presenta con la pobrezafilia se aleja radicalmente de los estándares de glamour y de esplendor que, por ejemplo, las revistas como Playboy han tratado de imprimir desde mediados del siglo pasado. En contraste, las imágenes de la pobrezafilia no preparan con detenimiento la ambientación, ni buscan imitar espacios ostentosos y confortables en donde aparezcan los cuerpos femeninos.

Parte de la reflexión detrás de este artículo se realizó con base en el estudio de las imágenes que han aparecido en internet bajo la palabra "pobrezafilia" o "putipobres", que son designaciones utilizadas para quienes aparecen en estas iconografías. Estos registros fueron tomados de búsquedas en Internet para comprender mejor este fenómeno social. Asimismo, también es importante señalar que, para hacer este análisis, no se tomaron en cuenta videos bajo esta categoría. Finalmente, se debe mencionar que, a la fecha, no es sencillo encontrar documentos académicos, en inglés o en español, que ayuden a comprender mejor este fenómeno.

\section{METODOLOGÍA}

Las técnicas que se utilizan para analizar un evento particular dependen de muchos factores entre los que se encuentran el acceso a la información, los recursos económicos con los que se cuentan, las preferencias de quien investiga, el momento histórico que se analiza, etcétera. En el caso específico de la presente investigación, se escogió utilizar la combinación de la revisión de material bibliográfico, así como fotografías que aparecen en Internet sobre el tema que aquí se pretende ahondar. Lo anterior se decidió de esa manera no solo por la gran cantidad de imágenes sobre la pobrezafilia que existen en Internet, sino también porque se consideró que este era un medio adecuado para realizar una investigación exploratoria sobre esta materia. Estas representaciones, que pueden ser consultadas por cualquier persona alrededor del mundo en un buscador de Google, refieren a toda una red de sentido particulares, no solo para quien tomó la fotografía sino también para quien la subió a una página de alguna red social: "En la imagen fotográfica encontramos estereotipos, signos de estatus social, relaciones de poder $y$ formas sociales que son familiares a los miembros de la misma cultura" (de Alba, 2010, p. 51).

De hecho, desde hace muchos años, el análisis de fotografías ha estado legitimado como una forma de realizar exploraciones sobre los modos de comportamiento, la cultura, la vida cotidiana y los diversos simbolismos sociales (Jelin, 2014; Bericat Alastuey, 2011; de Alba González, 2010). Tal y como Jelin (2014) lo recuerda "desde sus inicios", las ciencias sociales emplearon este recurso en los "estudios antropométricos o descripciones etnológicas" (Jelin, 2012, p. 60) como una forma de entender otras culturas y sacar conclusiones sobre ellas. Sin embargo, la investidura de aquello que se consideraba como conocimiento científico no impidió que, en muchas ocasiones, también se realizaran extrapolaciones racistas, misóginas $y$ discriminatorias de todo tipo por parte de los investigadores. Lo anterior no implica que las ciencias sociales no puedan seguir haciendo uso de este recurso para sus indagaciones, pues como cualquier método de investigación, estos siempre están impactados por múltiples factores contextuales.

La presente investigación se realizó principalmente a través de la revisión de imágenes aparecidas en Internet bajo la designación de "pobrezafilia" o "putipobres". La cantidad de fotografías que se puede encontrar bajo estas clasificaciones es muy amplia por lo que se tomaron en cuenta alrededor de 50 imágenes, las cuales no presentan claridad sobre el lugar 
donde fueron tomadas ni sobre la identidad de quien la subió a Internet u otros detalles sociodemográficos de sus protagonistas. En este trabajo el método a tomar en cuenta incluyó las siguientes premisas:

La selección de un corpus fotográfico permitirá observar el sistema de sentido del grupo social responsable de su producción. El método consiste en hallar las unidades de sentido en el corpus, identificar disyunciones elementales en tales unidades, así como las asociaciones entre éstas, para finalmente elucidar la estructura 0 modelo global de sentido del conjunto de las unidades. (de Alba, 2010, p. 52)

Las fotografías fueron analizadas buscando rasgos comunes entre ellas y proponiendo relaciones entre dichas coincidencias. Asimismo, también se revisaron imágenes de la revista Playboy, que habían servido para plantear un análisis anterior sobre la pornografía y el legado de Hugh Hefner (Sequeira, 2018). Por todo lo anterior, el análisis de materiales fotográficos se propone como un medio valioso para proponer una comprensión inicial sobre el fenómeno social que aquí se desea analizar.

\section{LA IMAGEN COMO HERRAMIENTA PARA PRODUCIR DESEO}

Entender la importancia que le ha otorgado a la iconografía es fundamental para realizar este tipo de teorizaciones. El historiador del arte alemán Hans Belting, en su libro Imagen y culto (2012), teorizó sobre la fuerza de la imagen desde el ocaso de la Antigüedad y hasta la Edad Media. Mediante su revisión de imágenes cristianas les atribuyó no solo simbolismos identitarios de pertenencia a una religión y a unos valores determinados, sino también a potencialidades de sanación a través de su veneración. Parte de su trabajo se basó en escudriñar y contextualizar las imágenes religiosas "que durante mucho tiempo fueron las únicas existentes" (Belting, 2012, p. 12). A diferencia de la palabra escrita en la Biblia que era comprendida a través de la lectura o la audición, las imágenes fueron, $y$ siguen siendo, interpretadas por medio de su visualización que procura darle sentido a la existencia. Al respecto, Belting argumenta que desde que el cristianismo pasó a formar parte de la religión del Estado, la iconografía religiosa ofreció a los emperadores la oportunidad de darle uniformidad y afinidad a las sociedades. Es decir, una imagen nunca es un mecanismo que solamente se mira, sino que también ofrece sentido y unidad ${ }^{1}$.

En nuestras sociedades donde abundan las imágenes, no solo religiosas, sino principalmente con un fuerte asidero en el mundo laico, es necesario comprender sus efectos y las "producciones de verdad" que pretenden ofrecer a las personas. Algunas redes sociales como Snapchat o Instagram proporcionan un lugar protagónico a las representaciones pictóricas y videos que se convierten en formas comunes de comunicación entre las personas. Sin embargo, mucho antes de esto ya el capitalismo utilizó este tipo de estrategias iconográficas para provocar en las personas toda una suerte de sensaciones que generaron preceptos de sentido.

En su investigación sobre la producción del capitalismo industrial de las primeras décadas del siglo xx en Colombia, Santiago Castro Gómez (2009) proveyó un lugar fundamental al análisis de las imágenes, en general y a la publicidad, en particular. Desde su perspectiva es incorrecto pensar en las imágenes como una estrategia que tergiversa la realidad, sino más bien que "desencadenan identificaciones y producen el deseo de materializar unos estilos de vida" (2009, p. 56). En este caso, el capitalismo necesitó de estas formas iconográficas para movilizar en las personas ciertas emociones. De hecho, tal y como lo menciona el autor, las imágenes publicitarias, más que buscar impactar la parte racional de la ciudadanía, intentaron "movilizar sus afectos" (Castro, 2009, p. 210) para producir ciertos efectos de cercanía a esos intereses.

\footnotetext{
1 "Sería, pues, un error considerar las imágenes - como más tarde defendieron los teólogos en la querella iconoclasta - simplemente como objetos de contemplación religiosa, dado que siempre se emplearon para fines tan tangibles - desde la defensa contra el mal o la curación, hasta la defensa del Imperio-." (Belting, 2012, p. 65).
} 
En este sentido, las imágenes de belleza también buscan provocar una serie de reacciones variadas en las personas. Para Wolf, la ofensiva contra el feminismo de finales del siglo 20 se empeñó en usar las "imágenes de la belleza femenina como un arma política contra el avance de las mujeres" (Wolf, 2002, p. 10). De acuerdo con su perspectiva, el "mito de la belleza femenina", que en tiempos anteriores estuvo limitada por la iconografía religiosa que se encontraba básicamente en las iglesias, fue propagada exponencialmente a una gran cantidad de mujeres gracias a la fotografía que difundió masivamente modelos asociados a ideas de "perfección". De hecho, la autora señala como una fecha importante la década de 1840 que es cuando se difunden "las primeras fotografías de prostitutas desnudas" $y$ años después una serie de "anuncios con imágenes de mujeres 'hermosas" (Wolf, 2002, p. 15).

Con el pasar del tiempo y cada vez más fuerza, este tipo de iconografía femenina fue difundida, y con ello, se propagó la imaginería de representaciones estereotipadas de la belleza. Para la autora, la sexualización de las mujeres proliferó gracias a la aparición de revistas como Playboy, la cual desde la década de 1950 inició con las imágenes y asociaciones glamurosas de mujeres en ambientes atractivos. Para la década de 1980, el emporio empresarial de Playboy también vio en las mujeres posibles compradoras de sus productos y utilizó la misma sexualización que se hizo sobre ellas como un gancho para provocar su deseo y "en ausencia de otras imágenes sexuales, muchas mujeres llegaron a creer que debían tener ese rostro, ese cuerpo, para lograr ese éxtasis" (Wolf, 2002, p. 135).

Es importante comprender que las ideas detrás de Playboy y de su creador Hugh Hefner no son recursos investigativos obsoletos para quien desea entender la sexualidad, sino que se han convertido en piezas necesarias para interpretar el rompecabezas que generó al sujeto sexual de nuestros días (Sequeira, 2018). Hefner y el imperio Playboy ayudaron a producir cierto tipo de identidad masculina $y$ femenina que reñía con la vivencia anterior de la década de 1950 en Estados Unidos. A través de esto, se generaron identidades cercanas al hombre soltero (playboy) y la mujer que buscaba ser sexualmente liberada (playmate) y que posteriormente impactarían la vivencia de miles de personas alrededor del mundo (Preciado, 2010). En una entrevista, el mismo Hefner mencionó: “Es este el paraíso que yo estaba planeando? Puedes apostar. Pero hay una sorpresa - esto es lo que ellas quieren (...). Con muchas de estas chicas ellas han fantaseado sobre ser parte de esto." (Vanity Fair, 2001, p. 282). La creación de estas ideas imprimió un interés particular por desear mostrar el cuerpo y no avergonzarse de ello.

\section{PLAYBOY Y LA PORNIFICACIÓN DE LA POBREZA}

Una sociedad como la nuestra está cada día más saturada de imágenes pornográficas o altamente sensualizadas, donde se promueven las subjetividades deseantes que erotizan los cuerpos normalizados y lo exponen en múltiples espacios (en las redes sociales, en la intimidad de una relación de pareja, en sitios que monetizan su consumo como OnlyFans, etc). Estas situaciones se ven magnificadas en programas que aparecen en la televisión por cable o en los servicios de suscripción como Netflix, los cuales exportan ciertos modelos de belleza estereotipadas a todos los rincones del planeta, donde América Latina no es la excepción.

Como parte del capitalismo liberal —que utilizó a la libertad personal como un recurso fundamental para sugerir que cada quien es la mayor limitante para poder alcanzar la felicidad verdadera - se ha facilitado la creación de subjetividades que convierten al erotismo personal y la belleza normalizada en estándares que rigen la existencia. De hecho, estas ideas han acuerpado el deseo de muchas mujeres jóvenes de obtener trabajos donde el cuerpo y el erotismo son los requisitos indispensables para el currículum y el triunfo personal. En esta misma línea, ha sido interesante notar el avance de intereses laborales en mujeres, que van desde convertirse en una celebridad, en una modelo, una bailarina stripper o una estrella porno $(\mathrm{Co}-$ chrane, 2005).

Como se detallará más adelante, la pobrezafilia no se basa en iconografía de fotografías glamurosas parecidas a las que promovió Playboy. Tampoco se busca editar las imágenes 
a través de Photoshop, para cubrir lo que se desea esconder en cualquier campaña publicitaria o "revista para caballeros". Sin embargo, existe una resonancia en este tipo de iconografía que se funda en la aparición de cuerpos inclinados a mostrarse como sujetos de deseo y erotismo, aunque sea en ámbitos domésticos, $y$ que luego terminan por ser distribuidas en diferentes páginas de internet. En todo caso, lo cierto es que este tipo de expresión gráfica se basa en un uso de imágenes erotizadas que podrían caber bajo el rango de una "pornificación de la pobreza". En este sentido, las playmates $y$ las personas que aparecen en la tendencia de la "pobrezafilia" son dos caras de una misma moneda. Dicho de otro modo, ambas han sido influenciadas por lógicas similares de producción del deseo y de la sexualidad.

El legado de Playboy implica herencias que promueven la aspiración de mostrarse como un sujeto cargado de sensualidad, un interés de masculinidades $y$ feminidades hipersexualizadas; un gusto por la confesión corporal erotizada, un deseo por la aparición de imágenes que exalten la belleza física normalizada, un interés por el emprendimiento personal que permita recompensas a base de la explosión de sensualidad estandarizada. En este sentido, de acuerdo con Mulholland: "La pornificación ha llegado a denotar la escalada y la presencia pública generalizada de la iconografía pornográfica en una amplia gama de medios $y$ de representación popular" (Mulholland, 2013, como se citó en Tyler y Quek, 2016, p. 3).

En este sentido, $y$ de acuerdo con Paasonen et al. (2007), el proceso de pornificación implica tres niveles que ayudan a entender su crecimiento. El primero se genera por la producción de cambios y desarrollos en la tecnología que han fomentado una expansión en la pornografía. El paso de la pornografía en Internet, por ejemplo, ha facilitado su difusión no solo gráfica, sino también de valores y estéticas. Cualquier persona sin distingo de edad, género, etnia o clase social puede acceder a diversos contenidos eróticos en Internet; solamente se necesita un dispositivo tecnológico para ingresar a grabaciones gratuitas o a imágenes de diferentes géneros pornográficos.
Segundo, con el paso del tiempo, las regulaciones de muchos países se flexibilizaron con relación a la pornografía entre adultos, lo cual ayudó a que sus contenidos también se difundieran. Hoy, diversos tipos de pornografía pueden ser encontrados en televisión por cable, en periódicos de sucesos o en eventos de pay-per-view.

Tercero, finalmente se produce una sexualización de la cultura donde la pornografía o sus valores se convierten en uno de los símbolos por excelencia de libertad sexual. La pornografía se funde con muchas formas de representación sexual y sus límites se diluyen haciendo de ello un aval de lo que McNair (2004) llamó porno chic, y que se produce cuando la representación pornográfica o de lo pornográfico toma un lugar central en la cultura. La pornificación, la cual se desarrolla bajo este tercer nivel, también se revela bajo la aparición de estrellas del mundo pornográfico en la categoría de celebridades. De hecho, bajo las figuras de Hugh Hefner, la actriz porno Jenna Jameson, o las reconocidas Holly, Kendra y Bridget (las tres novias de Hefner que se hicieron famosas por aparecer en el reality show llamado Girls of the Playboy Mansion) se pueden apreciar ejemplos de personajes que, a pesar de provenir del mundo pornográfico, ingresan a la farándula y se convierten en referentes culturales, sexuales y eróticos para millones de personas alrededor del mundo.

Para los contextos latinoamericanos que consumen este tipo de programas a través de la televisión, el internet o las redes sociales, los modelos promocionados de belleza y sensualidad no les son ajenos. De hecho, los consejos de las estrellas porno, donde ellas se convierten en las figuras legitimadas como la autoridad en la sexualidad más placentera, también llegan a países de América Latina, ya sea por la traducción al español de programas que se pasan por cable, como los que fueron difundidos por HBO de la actriz pornográfica Katie Morgan, o las alusiones sexualizadas que intérpretes pornográficas como la colombiana Esperanza Gómez han ayudado a difundir (Sequeira, 2018). Es decir, América Latina no puede considerarse una burbuja que está ajena de estas influencias, 
sino que también es permeada por estándares y modelos de sensualidad normalizados.

En este escenario de sexualización de la cultura, la pobreza también ha sufrido procesos de pornificación bajo la categoría de la "pobrezafilia". Ella se transforma en la nueva expresión pornográfica que surge de la vida cotidiana de personas en América Latina con contextos habitacionales humildes. Las imágenes que las jóvenes se toman en estos escenarios no es pornografía por sí misma, sino que sufre un proceso de pornificación, donde la ambientación termina por ser la protagonista. Los entornos empobrecidos se resignifican bajo estándares pornográficos y su lectura ya no puede ser solo analizada por los expertos en pobreza. Las protagonistas de estas imágenes no son modelos profesionales, sino mujeres jóvenes con acceso a celulares que viven en sitios concentrados en los anillos de marginalidad de ciudades latinoamericanas.

Los estudios en pornografía o porn studies han logrado instalarse en centros universitarios de varios países y han brindado varias reflexiones sobre el complejo mundo de los códigos y efectos pornográficos. No obstante, en el caso de América Latina, aún falta una mayor consolidación de este tipo de centros investigativos o de investigadores especializados en estas temáticas que se alejen de las clásicas alusiones que piensan a la pornografía como un subproducto cultural que no merece ser analizado. En este sentido, la relación entre materiales erotizados y la clase social de sus protagonistas, así como muchos otros temas, debe seguir estudiándose en profundidad. De hecho, como se mostrará a continuación, esta falta de interés específicamente con las personas que viven en condiciones de pobreza presenta una nueva complejidad en el estudio de la pobrezafilia; sin embargo, muestra también una veta interesante para ampliar este tipo de reflexiones.

\section{LA POBREZA, LA SEXUALIDAD Y LA PORNOGRAFÍA}

Existen más intereses investigativos en reflexionar sobre la correspondencia que se desarrolla entre la pobreza y la prostitución que entre la pobreza y la pornografía (por ejemplo, revisar: Arturo-Zarama, y Cante-Maldonado, 2017; Cobo, 2016; Condiza y Hernández, 2012; Infeld, 2009). Cabe sugerir que lo anterior se debe a que el estudio de la prostitución se ha presentado como prioritaria en la lucha de organismos gubernamentales y no gubernamentales contra la trata de personas o la explotación sexual comercial, donde la eliminación de la prostitución forzada podría incluir otras acciones como la elaboración de material pornográfico bajo amenazas. En todo caso, aunque se sabe que existe prostitución de mujeres de clase media y alta que se cotiza en los más altos niveles (Bernstein, 2007; Schifter, 2007), cuando se busca una relación académica entre pornografía y pobreza se tiende a centrar el análisis casi exclusivamente en tipos de pornografía catalogadas como delito, tal y como ocurre con la pornografía infantil.

Ya que esta última producción de materiales eróticos sobre menores de edad no concierne al presente trabajo, dicha vertiente no será tomada en consideración para este documento. En cambio, este estudio se centrará en otra situación: explorar el fenómeno donde la pobreza y la pornografía se relacionan y comulgan en la pobrezafilia. En todo caso, queda en evidencia que, más allá de los casos sancionables donde niños, niñas o adolescentes son obligados a exhibirse frente a un lente de cámara, existe aún un terreno digno de investigar, donde pornografía y pobreza puedan interrelacionarse.

De esta manera, en cuanto a estas dos categorías, las personas pobres solo son tomadas en cuenta en la reflexión académica de la pornografía cuando están completamente indefensas, vulnerables o carentes de la posibilidad de decidir, como pasa en el caso de la pornografía infantil. En este sentido, como lo ha recordado recientemente Judith Butler (2017), la categoría vulnerabilidad ha sido asociada casi automáticamente con ciertas poblaciones como las mujeres y las personas pobres, lo cual produce la sensación de que siempre están necesitadas de instituciones paternales para cuidarlas en vista de su percibido estado de debilidad.

La visión que ha relacionado pornografía $y$ pobreza en la academia ha sido heredada por 
la perspectiva que ha señalado que la primera solo debe ser reflexionada si el objetivo último es, en todo caso, eliminarla. De hecho, para una feminista antipornógrafa como MacKinnon (2010) existen variables que deben entenderse juntas al trabajar estos temas: "Prostitución y pornografía se alimentan, existen a causa de, $y$ promueven la combinación de la pobreza basada en el sexo y la violencia de género." (MacKinnon, 2010, p. 505). Para ella, la pornografía solo puede ser comprendida como una forma de "sexualidad abusiva" (MacKinnon, 2010, p. 506), donde este tipo de expresión sexual es siempre e invariablemente una carga social y solo puede ser explicada a través de la violencia. Esta visión es la perspectiva que ha caracterizado muchos de los abordajes relacionados con esta temática; como resultado, la investigación sobre lo pornográfico ha quedado reducida a dicha línea de discusión.

Por tanto, este trabajo evita tomar la misma posición teórica que expresa MacKinnon: aquella que plantea a la pornografía como el mal de todos los males y como un subproducto cultural que no merece la pena ser analizado. Más bien, este documento propone que la pornografía debe ser reflexionada como un producto social creador de subjetividades, una fabricación humana que personifica un componente pedagógico significativo, un centro de deseo y representación fundamental para muchas personas y que, en el caso de las sociedades, se ha convertido en un centro básico de saber y de nociones de "verdad".

Como se mencionó anteriormente, no es común encontrar estudios sobre pornografía y personas mayores de edad en condición de pobreza, aunque algunas veces el análisis se hace de forma tangencial. En un ejemplo de ello, un documento relativamente reciente analiza el porno zoófilo de Brasil (Díaz-Benítez, 2014). En él se detallan cinco grupos de mujeres quienes son sus protagonistas. Entre ellas se encuentran travestis, mujeres mayores, jóvenes, gordas y también aquellas que presentan una condición de vulnerabilidad económica. Para las páginas web que promocionan este tipo de pornografía, las "necesidades económicas extremas” (Díaz-Benítez, 2014, p. 67) parecieran ser la justificación del porqué alguien estaría interesado en realizar este tipo de trabajo, lo cual genera la idea de que la pobreza es un catalizador de conductas despreciables.

También se pueden encontrar análisis sobre estas dos variables (pobreza y pornografía) bajo los mismos cánones de la lógica antipornográfica que buena parte del feminismo radical ha ayudado a difundir. Por ejemplo, en una tesis que buscaba analizar una serie de revistas pornográficas de principios del siglo Xx en Brasil y Chile, se determinó que las revistas estudiadas eran consumidas en ambos países sobre todo por hombres de clase media o clase acomodada. Ante esta situación, la autora desprende la siguiente reflexión: "Así, la pornografía sería el arte erótico de los pobres, pobreza que más que referirse a las condiciones materiales de existencia, nos habla sobre su pobreza espiritual, cultural y libidinal." (Ledezma, 2010, p. 62). Nuevamente, aquí el consumo de pornografía es considerado per se como un estado de "indigencia moral" en personas con graves falencias éticas, pero no necesariamente como elemento fundamental para el análisis social de la sexualidad $y$ del sujeto deseante.

La pobreza también se asocia a la pornografía bajo la situación reprochable que ha sido denunciada como la "pornografía de la pobreza". Esto se trata de "una táctica utilizada por organizaciones de caridad y sin fines de lucro para lograr la empatía y contribuciones de donantes al mostrar imágenes con fines de explotación de gente que vive en condiciones menesterosas." (Dortonne, 2015). Es común encontrar este tipo de técnicas propagandísticas enfocadas en países africanos que sirven para buscar financiamiento a ciertos proyectos basándose en cuerpos de personas empobrecidas y con evidentes signos de abandono social.

Para resumir, se puede señalar que la visión que existe sobre la relación entre pornografía y la pobreza continúa desarrollando ideas sobre: a) la vulnerabilidad a priori de estas personas, desprendiéndolas así de cualquier capacidad de decisión; b) la clasificación de la pornografía como un hecho intrínsecamente negativo y nocivo; c) la conexión de pobreza y pornografía con algún tipo de "pobreza moral". 
El estudio de la pobrezafilia en este documento corresponde a un esfuerzo de salirse de los cánones tradicionales de análisis donde las personas de clase baja son sujetos completa y exclusivamente frágiles, o de la visión que promueve la lógica antipornográfica. Este artículo busca complejizar las nociones tradicionales del análisis pornográfico mediante los apoyos que otras teóricas dentro del feminismo han pretendido plantear $y$ cuestionando lo inadecuado que ha sido pensar a la pornografía como un elemento insignificante o despreciable para la academia (Preciado, 2008), o que han criticado la recurrencia de las investigaciones en posicionarse desde las nociones dicotómicas de "poder malo" o "poder bueno", las cuales suelen desprendense de estos análisis (Allen, 2001). A continuación, se desarrollará un análisis de las imágenes encontradas en internet sobre esta categoría.

\section{DE LAS PLAYMATES A LAS PUTIPOBRES}

Como se ha esbozado hasta aquí, la pobrezafilia es un fenómeno de exposición fotográfica o de elaboración de videos donde aparecen principalmente mujeres jóvenes bajo posturas sensuales en escenarios humildes, que hace deducir al espectador la posición económica que poseen sus protagonistas ${ }^{2}$. Aunque la mayoría de las imágenes muestran una erotización del cuerpo, otras, en una proporción mucho menor, han sido clasificadas bajo esta categoría,

$\overline{2}$ Si uno se pregunta cómo es que han llegado estas imágenes a internet, es posible pensar que provienen por lo menos de dos fuentes. Primero, estas han sido compartidas por celular a parejas, pretendientes o amistades $y$ que estos a su vez las han vuelto a compartir con terceros, llegando a aparecer por estas distribuciones exponenciales en Internet bajo las categorías aquí mencionadas. En segundo lugar, también es posible que las personas que allí aparecen las tomaran para luego ser subidas a sus redes sociales $y$ recibir algún tipo de aprobación de sus amigos en línea. Probablemente, quienes allí aparecen no tienen conocimiento de que sus retratos han sido vistos por millones de personas bajo estos descriptores y que seguirán estando disponibles por tiempo ilimitado en diversas páginas que se especializan en este tipo de imágenes. pues simplemente presentan jóvenes en este ambiente. Si la pornografía tradicional supone "la exposición de lo espectacular a partir de la exageración y del realismo simultáneamente" (Díaz-Benítez, 2013, p. 95), la pobrezafilia busca acercarse al "realismo" que se supone contienen estas imágenes $y$ donde se magnifican ciertos escenarios empobrecidos. Para febrero de 2021, el buscador de Google encontró bajo el término "pobrezafilia" alrededor de 15400 resultados y para "putipobres" cerca de 91 200. Esta es una tendencia que se presenta más en redes sociales como Twitter, pero que también aparece en otras páginas como Taringa! o Facebook. En realidad, es difícil saber si alguno de estos casos ha llegado a los tribunales de algún país latinoamericano o, incluso, si quienes allí aparecen saben que sus imágenes han sido viralizadas, pues sobre esto no existe mucha información.

En todo caso, es importante recalcar que en las fotografías eróticas o erotizadas tradicionales (ya sea pornografía u otro tipo de exposición como el que hacen las actrices y modelos en las revistas), el cuerpo que se exhibe es un poco más importante que el ambiente que está detrás de este. De hecho, ambos son importantes, pero en varias ocasiones, una pared monocromática o una tela de fondo (como en el caso de Marilyn Monroe en el primer número de Playboy) son suficientes para leer a la protagonista bajo los estándares de los cuerpos sexualizados. En este sentido, en la pobrezafilia, aunque el cuerpo de la mujer se creería lo central, el ambiente termina por sobreponerse $y$ convertirse en la pieza fundamental de la imagen.

A pesar de que sin un cuerpo erotizado la fotografía sería solamente una muestra más de un contexto empobrecido en América Latina, el escenario donde se toman estas imágenes (las casas o los barrios) terminan por obtener el primer plano de la iconografía y los espacios acaban por pornificarse. El ambiente logra subsumir las poses sensuales que en cualquier otro escenario sería lo principal. De esta forma, las jóvenes de las fotografías o videos en cuestión, al ser catalogadas en las redes sociales o las diversas páginas de internet donde aparecen 
este tipo de categorizaciones, dejan de ser integrantes de una comunidad empobrecida, para ser transformada en "putipobres", como se le designa de forma peyorativa.

Un elemento interesante de añadir es que el término pobrezafilia pareciera no tener un referente en el idioma inglés. Aunque su traducción podría ser povertyphilia, lo cierto es que no existe casi ningún documento académico que dé cuenta de esta situación en esa lengua. Este es un fenómeno que parece representarse exclusivamente en barrios pobres de América Latina. De hecho, según el periódico mexicano Vanguardia (2015), la pobrezafilia inicia en el 2015 y más, específicamente, se comienza a desarrollar en México, extendiéndose posteriormente a países como "Costa Rica, Colombia, Chile y Argentina". Sin embargo, en la publicación digital, no señala de dónde se obtienen los datos para tal afirmación.

Aunque "filia" remita a un gusto o atracción por algo, no se pueden hablar de sentimientos claros con relación a la pobrezafilia. Es más posible que las imágenes o videos muestren expresiones de burla, de desprecio, de desagrado; pero también de atracción y erotismo hacia las jóvenes de las fotografías, como se puede apreciar en muchas de las páginas donde esta categoría es la principal atracción. Asimismo, las imágenes que se producen en habitaciones donde prima la desorganización, el tumulto o los enseres apilados podrían trasmitir emociones contradictorias. Ciertamente, en la pobrezafilia, se designa a quienes son parte de él a través de nombres que terminan por ser calificativos despectivos. Algunas de estas designaciones son "putipobres" o "Misseria", que suelen ser usados como hashtags para las búsquedas en internet.

Si se quisiera ser más específicos sobre algunas de las características que se pueden desprender de las imágenes, se debe decir que algunas se resumen en las siguientes:

a) Sus protagonistas: la pobrezafilia parece ser un fenómeno donde aparecen principalmente mujeres jóvenes. En la gran mayoría de las ocasiones solo se muestra una chica por cada fotografía. No obstan- te, en algunos casos se pueden observar dos o tres muchachas que juegan frente a la cámara bajo la idea de la erotización de prácticas sexuales entre mujeres. En las imágenes de la pobrezafilia es posible observar que casi siempre las mujeres son muy jóvenes, con cuerpos que se presentan en posturas sensuales y luciendo ropas ajustada y corta, o en ropa interior. Sin embargo, esto no siempre es absolutamente necesario; basta mezclar la ambientación que se ha descrito con mujeres de la zona para ser catalogado bajo ese calificativo. También es importante señalar que, en algunas ocasiones, se pueden encontrar imágenes donde aparecen hombres con ambientaciones típicas de esta tendencia. Al igual que en los casos previamente mencionados, ellos son generalmente jóvenes; asimismo, se muestran con el torso descubierto y bajo los escenarios antes señalados.

b) La ambientación: en una gran cantidad de las ocasiones, para el caso de estas mujeres, uno de los escenarios principales de las fotografías suele ser el dormitorio. Un segundo escenario que también aparece frecuentemente son las cocinas o las salas de las casas. Finalmente, algunas de estas imágenes se presentan en exteriores como los patios, donde suele observarse al fondo las viviendas humildes. En el caso de los hombres que son partícipes de esta tendencia, no es tan claro determinar en qué apartado de la casa se encuentran, pero en varias ocasiones se muestran en exteriores. En todo caso, la ambientación fotográfica general muestra escenarios con paredes desteñidas, rayadas, mal pintadas, sucias, con base de ladrillos y otras que parecen haber quedado en obra gris. En las paredes suele verse colgados símbolos religiosos, calendarios, alguna tela, papel periódico, posters de un grupo musical o algún banderín de un equipo de futbol. En los dormitorios es común percatarse que en las paredes hay bolsos, o se 
muestra ropa apilada o colgada de forma desarreglada. Lo mismo ocurre cuando se exponen los pisos de las casas, donde también parece que el desorden es una característica importante pues sobresalen los platos, papeles o ropa tirada en ellos. En varias ocasiones, las camas destacan por no estar tendidas o presentar múltiples prendas amontonadas sobre ella. En las cocinas se revelan trastes apilados $y$ mezclados en torres. Cuando los techos son visibles se los presenta sin cielo raso, con latas de zinc oxidadas, con moho o con algún hongo.

c) Modo de captar las imágenes: es muy probable que la mayoría de los retratos se hagan con los celulares de quienes aparecen en las imágenes (selfies) o con celulares de personas cercanas a ellos (parejas o amistades). Con la democratización del registro fotográfico que se ha realizado con estos aparatos, es muy probable que casi todas las imágenes se hagan de esta manera. En todo caso, existe un peso relativamente similar entre quienes se toman fotografías a ellos mismos (selfies) y quienes ocupan de otra persona para realizarlo. Como la calidad de las imágenes no tiene que ser óptima ni es imprescindible utilizar una buena iluminación (como sí ocurre en campañas publicitarias o imágenes de Playboy) el celular es más que suficiente. Basta con que se deje mostrar el ambiente y el cuerpo de las jóvenes para que la fotografía ingrese al registro de lo pornificado.

d) La indumentaria: es frecuente que las imágenes muestren mujeres en lencería y babydolls, pero también con pantalones cortos (shorts), jeans ceñidos al cuerpo o vestidos ajustados y pequeños. Asimismo, es común observar minifaldas, blusas escotadas o reducidas en estas jóvenes. El calzado puede variar desde el tacón alto, sandalias o botas, hasta estar sin zapatos. De hecho, este último es un detalle menor que no siempre se muestra. En algunas pocas ocasiones, las jóvenes aparecen desnudas, aunque esto tampoco es la norma. El maquillaje o el peinado de salón tampoco son protagonistas, aunque sí se observan muchos cabellos lacios o alaciados. Asimismo, como se había mencionado con anterioridad, generalmente los hombres suelen aparecer con el torso descubierto y con jeans. Algunos buscan bajarse un poco el pantalón y otros simplemente desean mostrar sus brazos y abdomen definidos.

El fenómeno permite mostrar complejidades del mundo tecnológico en el que se vive, donde la confesión fotográfica se hace más que evidente al buscar mostrar la belleza, la sensualidad y el erotismo de sus protagonistas; donde miles de fotografías pueden ingresar al registro que existe en internet sin tener el consentimiento de estas personas o sin conocer que son una tendencia de ciertas páginas.

\section{OTRAS COMPLEJIDADES DEL FENÓMENO DE LA POBREZAFILIA}

La pornificación de la pobreza presente en la situación que se ha nombrado como la pobrezafilia muestra una interesante reflexión de fenómenos actuales (como, por ejemplo, elementos sobre la tecnología, sobre modelos de erotismo, las desigualdades sociales, la construcción de la masculinidad y la feminidad, el emprendimiento personal, etc.). Entre ello, uno de los elementos a tomar en cuenta se presenta por la reflexión de ciertas complejidades que se han creado bajo esta misma situación.

En primer lugar, los hashtags de esta tendencia buscan interconectar dos categorías que parecen contraponerse, al menos intentando ser creativos con el lenguaje ante la situación de la pobreza pornificada. Algunos como \#tanpobreytanrica o \#Misseria, apuntan a remarcar esta situación. La pobreza (económica) hace aquí un juego de palabras con el atractivo sensual (entendiendo que, en varios países de Latinoamérica, se utiliza la noción "rica" como un término sexualizado y que no tiene que ver aquí con acceso a capital monetario). Se propo- 
ne entonces que se puede ser atractiva $y$ a la vez no tener mucho dinero.

Asimismo, otra de las etiquetas que ha sido dada a esta tendencia y sobre las que se busca mofarse, es la que tiene que ver con la posibilidad de ser una reina de belleza (Miss Universo, por ejemplo), y concebir a sus protagonistas en lugares empobrecidos (miseria y Misseria). Su relación con la miseria es claramente una forma de ridiculizar a estas jovencitas exaltando solamente su cuerpo sexualizado. En todo caso, es interesante mostrar la forma en que ambos términos o etiquetas refieren exclusivamente a categorías relacionadas a mujeres, precisamente porque la pobrezafilia descansa sobre todo en figuras femeninas erotizadas.

En segundo lugar, la misma expresión de pobrezafilia comporta un juego burlesco de palabras en el que el amor o la atracción (filia) a la pobreza, no es exactamente lo que caracteriza a esta tendencia. El sarcasmo a las condiciones de vivienda o de existencia de personas humildes se mezcla con la sexualización que se hace sobre las personas que allí aparecen. Otro tipo de imagen completamente distinta sería la que se produciría si se muestra una anciana cuidando un fogón o barriendo el piso en un contexto como el que se ha descrito anteriormente. Lo que le da forma a la pobrezafilia es el ambiente que se suma a las personas jóvenes sexualizadas que allí aparecen. Bajo estas condiciones, se incentiva el proceso de la pornificación de la pobreza, donde esta última, para ser visibilizada solamente lo logra bajo estándares pornográficos.

En tercer lugar, un ejemplo de una dicotomía -que no se refuerza en la pobrezafilia, sino que se ve comprometida porque solo se toma en cuenta una de las variables- es la que se presenta bajo la clásica separación femenina entre la puta y la virgen. En términos generales, bajo este descriptor, cualquiera que aparezca en estas imágenes (generalmente mujeres jóvenes) son inmediatamente sexualizadas y catalogadas con el nombre despectivo de putipobres. Es decir, cualquier persona que se muestre bajo esta etiqueta queda subsumida bajo estándares sexualizados o hipersexualiza- dos. Tal y como lo propuso Naomi Wolf (2002), la juventud en las mujeres ha sido convertida en un bien valioso, listo para ser explotados para mejorar su situación económica. De esta forma ellas y ellos no serán simplemente habitantes de un Estado, provincia o región de América Latina. Son cuerpos erotizados e incrustados en una clase social específica que son exhibidos y que movilizan sensaciones, al mismo tiempo, de deseo y de burla.

\section{CONCLUSIONES}

La relación entre la pobreza y la pornografía, que se expresan claramente en la tendencia de la pobrezafilia, se fortalece en un mundo donde existe una fuerte propensión a pensar la realidad a base de jerarquías contrapuestas. De hecho, la pornografía tradicional funciona siempre bajo la premisa de jerarquías poderosas. Esto se simboliza en los roles frecuentemente representados en este tipo de productos visuales donde aparecen papeles recurrentes de, por ejemplo, la secretaria y el jefe, el profesor y la alumna, el ama de casa $y$ el plomero, el sacerdote y la monja. De hecho, esta relación se presenta en Playboy con Hefner $y$ las conejitas o los playboys y las chicas de al lado. En la pobrezafilia también se muestra la tendencia de percibir a las jóvenes que se encuentran en estos espacios empobrecidos como parte de las escalas más bajas del orden jerárquico social, sexual, cultural y económico. Quienes las miran o las postean se piensan como superiores en todos los niveles sociales.

Poco importa entonces si las mujeres que aparecen en las imágenes que se muestran en las búsquedas de Google bajo el descriptor de pobrezafilia saben que ahora sus fotografías son públicas. Tampoco importa esclarecer con exactitud si las imágenes fueron tomadas en México, Costa Rica o cualquier otro país de la región. Es probable de hecho, que sus protagonistas nunca lleguen a saber que se han convertido en una tendencia pornográfica o de pornificación, no tanto por ellas mismas, sino más bien por el ambiente donde las fotos fueron tomadas. En todo caso, estas imágenes terminan por contribuir a la jerarquización sexual que se promueve en muchas relaciones 
sociales y en la pornografía en general. Aunque consigan que muchas personas visualicen por algunos minutos escenarios habitacionales que representan modos de vida empobrecidos de América Latina, lo cierto es que esta contemplación pareciera seguir naturalizando las condiciones de vida $y$ los papeles sociales desiguales, pues la burla y la objetivación (no solo de cuerpos) es lo que prevalece en esta tendencia de Internet. La pobrezafilia se potencializa precisamente porque Internet permite que su distribución sea masificada y universalizada.

En este sentido, la reflexión sobre la imagen fotográfica en general ha provocado análisis relevantes. Por ejemplo, como fue denunciado por Susan Sontag (2006) y luego retomado por Butler (2010), cierto tipo de periodismo de guerra llamado "periodismo incorporado" promueve la limitación de imágenes que pudiesen tener efectos no deseados en la población general. Como pasó con la guerra de Irak, se acataron órdenes para no permitir la contemplación de muerte y destrucción que pudieran perturbar a la ciudadanía estadounidense y del mundo. Esta situación centralizó la discusión sobre regulaciones visuales y emocionales de temáticas sensibles.

Para Butler (2010), la interpretación que se puede hacer de una imagen "no se debe concebir restrictivamente en términos de un acto subjetivo" (p. 101). En el caso de la pobrezafilia, esta tendencia no implica un acto individual que fue masificado, sino más bien un complejo orden de relaciones que hablan de tendencias sociales $y$ visiones hacia aspectos tan complejos como la clase social, la feminidad o la masculinidad, las consecuencias problemáticas de las tecnologías, etc. Los efectos de este tipo de posibilidades iconográficas deben seguir siendo profundizados, quizá con investigaciones de orden cualitativo que permitan hacer entrevistas a sus protagonistas $y$ a quienes podrían interesarse por comentar o subir este tipo de documentos.

Quien sube la imagen a Internet, sin permiso de las mujeres que allí aparecen, queda completamente liberado de responsabilidad al perderse su rastro en la jungla que representa este tipo de interacciones tecnológicas. Si las jó- venes que han aparecido en dicha iconografía sexualizada son un reflejo de códigos sexualizados masificados para las mujeres, quienes suben las imágenes a Internet (posiblemente sin su autorización) son el reflejo de una problemática que también merece consideraciones particulares, y que representa, entre otras cosas, las jerarquizaciones de superioridad burlesca que pondera como inferiores las vidas de entornos económicamente precarizados. La burla de las imágenes supone que lo mejor que tienen estas mujeres es su cuerpo y su atractivo, y que su valía se encuentra precisamente en este tipo de coordenadas estereotipadas de belleza. Si la misma imagen fuera tomada por una actriz o modelo en otro tipo de ambientación, sus imágenes podrían ser vendidas en OnlyFans o en otro tipo de servicios de suscripción con contenido erótico y la burla perdería todo sentido de importancia.

En este documento, se ha intentado demostrar que el estudio de la pornografía o también de la pornificación de la vida cotidiana aún tiene mucho terreno para ser analizado. Los estudios que solo desean ver la pornografía o lo pornográfico como malo, desechable o pecaminoso deben ser trascendidos, porque precisamente no les interesa desgastarse con ningún tipo de análisis. Basta con sugerir que lo pornográfico en sí mismo es despreciable o es un acto de violencia y con ello termina el interés investigativo. Sin embargo, ya que esta expresión visual es tan importante en nuestras sociedades, su uso, consumo, manejo, disfrute, debe ser tomado en consideración por las investigaciones de las ciencias sociales para dar cuenta de su importancia a nivel cultural, económico y de simbolismos variados.

\section{REFERENCIAS}

Allen, A. (2001). Pornography and Power. Journal of Social Philosophy. 32(4), 512-531. http://web.a.ebscohost.com. una.remotexs.co/ehost/pdfviewer/ pdfviewer?vid=1\&sid=f17230f0-1cc0-4a7eaf63-24f8ca8a9ad8\%40sessionmgr4008

Arturo-Zarama, D. y Cante-Maldonado, F. E. (2017). Prostitución y desigualdad socioeconómica. Revista Eleuthera, 16, 
69-84. https://www.redalyc.org/jatsRepo/5859/585963499005/585963499005.pdf

Belting, H. (2012). Imagen y culto. Una historia de la imagen anterior a la edad del arte. Akal.

Bericat Alastuey, E. (2011). Imagen y conocimiento: retos epistemológicos de la sociología visual. Empiria. Revista de metodología de Ciencias Sociales, (22), 113-140. https://doi.org/10.5944/empiria. 22.2011 .87

Bernstein, E. (2007). Temporarily Yours: Intimacy, Authenticity, and the Commerce of Sex. University of Chicago Press.

Butler, J. (2010). Marcos de guerra. Las vidas lloradas. Editorial Paidós.

Butler, J. (2017). Cuerpos aliados y lucha politica. Hacia una teoría performativa de la asamblea. Editorial Paidós.

Castro Gómez, S. (2009). Tejidos oníricos: movilidad, capitalismo y biopolítica en Bogotá (1910-1930). Editorial Pontificia Universidad Javeriana.

Cobo Bedia, R. (2016). Un ensayo sociológico sobre la prostitución. Política y Sociedad, 53 (3), 897-914. https://core.ac.uk/download/pdf/81230022.pdf

Cochrane, K. (2005). Why porn is the new glamour. New Statesman, 134(4757), 34-35.

Condiza Plazas, W. E. y Hernández Reyes, E. P. (2012). Pobreza y prostitución en Boyacá, Colombia: una mirada desde los derechos humanos. Revista Colombiana de Sociología, 35(1), 83-95. https://www. redalyc.org/pdf/5515/551556229005.pdf

De Alba González, M. (2010). La imagen como método en la construcción de significados sociales Iztapalapa. Revista de Ciencias Sociales y Humanidades, 69, 41-65. https://www.redalyc.org/ pdf/393/39348726003.pdf

Di Cesare, M. (2007). América Latina: patrones emergentes en la fecundidad y la salud sexual y reproductiva y sus vínculos con la reducción de la pobreza. Notas de población \#84. Comisión Económica para América Latina y el Caribe (CEPAL). https://repositorio.cepal.org/bitstream/ handle/11362/12814/np 84011051 es.pdf?sequence $=1 \&$ isAllowed $=y$

Díaz-Benítez, M. E. (2014). Pornografía con animales y los límites de la sexualidad. Maguaré, 28(1), 51-78.

Díaz-Benítez, M. E. (2013). El quehacer porno en la construcción de imágenes de espectacularidad. Memoria y Sociedad. 17(34), 92-109.

Dortonne, N. (2015). Los peligros de la pornografía de la pobreza. CNN en Español. https://cnnespanol.cnn. com/2015/12/24/los-peligros-de-la-pornografia-de-la-pobreza/

Fernández Carvajal, D. (2011). Sexualidad y género en condiciones de pobreza. Editorial de la Universidad Nacional, Costa Rica.

Infeld, A. (2009). Pobres y prostitutas. Politicas sociales, control social y ciudadanía en Comodoro Rivadavia (1929-1944). Prohistoria Ediciones.

Jelin, E. (2014). La fotografía en la investigación social: algunas reflexiones personales. Memoria Y Sociedad, 16 (33), 55-67. https://revistas.javeriana.edu.co/index. $\mathrm{php} / \mathrm{memoysociedad/article/view/8313}$

Ledezma Salse, A. M. (2010). Visibilidad vedada: Cuerpos femeninos en la pornografía. Chile y Brasil (1913). [Tesis de Máster en Estudios Latinoamericanos]. Universidad de Chile.

MacKinnon, C. (2010). Gender. The future. Constellations: An International Journal of Critical \& Democratic Theory, 17(4), 504-511.

McNair, B. (2004). La cultura del striptease. Sexo, medios y liberalización del sexo. Editorial Océano.

Paasonen, S., Nikunen, K. y Saarenmaa, L. (2007). Pornification and the education of desire. En: S. Paasonen, K. Nikunen, y L. Saarenmaa (eds), Pornification: Sex and Sexuality in Media Culture (pp. 1-20). Berg Publishers.

Pacheco Sánchez, C. I. (2015). Agencia social, sexualidad y embarazo en menores de 15 años. Rev. Gerenc. Polit. Salud; 
14(29), 62-82. http://dx.doi.org/10.11144/ Javeriana.rgyps14-29.asse

Preciado, B. (2010). Pornotopía: arquitectura y sexualidad en "Playboy" durante la guerra fría. Anagrama.

Preciado, B. (2008). Testo Yonqui. Espasa Calpe.

Rostagnol, S. (2003). Representaciones y prácticas sobre sexualidad y métodos anticonceptivos. Hombres de sectores pobres urbanos. En S. Romero Gorski. (Comp.), Anuario de Antropología Social y Cultural en Uruguay 2002-2003 (pp. 39-55). Facultad de Humanidades y Ciencias de la Educación, Universidad de la República.

Schifter Sikora, J. (2007). Viejos verdes en el paraíso: Turismo sexual en Costa Rica. Editorial Universidad Estatal a Distancia.

Sequeira Rovira, P. (2018). Buscando ayuda en el porno. Reflexiones en torno a la porno-ayuda y al pastorado de Hugh Hefner. SEBILA.
Sontag, S. (2006). Sobre la fotografía. Suma de Letras.

Tyler, M. y Quek, K. (2016). Conceptualizing Pornographication: A Lack of Clarity and Problems for Feminist Analysis. Sexualization, Media, \& Society, 1-14.

Vanity Fair. (2001). Hugh Hefner's Roaring 70s. Vanity Fair. Advance Magazine Publishers Inc, pp. 238-245, 277-283.

Vanguardia. (6 de diciembre de 2015). Pobrezafilia: la nueva e inquietante tendencia en redes sociales. Vanguardia. https://www.vanguardia.com.mx/articulo/pobrezafilia-la-nueva-e-inquietantetendencia-en-redes-sociales

Wolf, N. (2002). The beauty myth: how images of beauty are used against women. Harper Perennial.

Fecha de ingreso: $13 / 10 / 2020$ Fecha de aprobación: 12/10/2021 
